Synthesis

\title{
Designing Landscapes for Performance Based on Emerging Principles in Landscape Ecology
}

\author{
$\underline{\text { Sarah Taylor Lovell }}^{1}$ and Douglas M. Johnston ${ }^{2}$
}

\begin{abstract}
We have proposed a framework for transforming landscapes to improve performance by integrating ecological principles into landscape design. This effort would focus on the development of multifunctional landscapes, guided by the rapidly growing knowledge base of ecosystem services provided by landscape features. Although the conventional approach to landscape ecology is based on a model that assumes poor ecological quality in the human-dominated matrix, a review of recent literature reveals important opportunities to improve the quality of the landscape matrix by increasing spatial heterogeneity through the addition of seminatural landscape elements designed to provide multiple ecosystem services. Taken alone, these individual elements might not appear to have a large impact on the environment, but when considered together within the entire landscape, the contribution could be significant, particularly when these elements are intentionally designed to improve landscape performance. Previous attention has focused on the value of large patches of native vegetation for conservation efforts. These efforts have included preserving those areas that still remain, restoring those that once existed, and providing connectivity between them. But great opportunities exist to improve the quality of the matrix by designing multifunctional elements throughout the landscape. Through a synthesis of knowledge in landscape architecture and landscape ecology, we have demonstrated some important applications of the landscape performance framework in urban and agricultural settings. Based on a review of the literature, we have suggested several methods of evaluating and monitoring landscape performance to determine the relative success of a designed landscape.
\end{abstract}

Key Words: agroecosystem; design guidelines; ecological design; ecosystem services; human-dominated; multifunctional landscape; multifunctionality; urban agriculture; urban ecology.

\section{INTRODUCTION}

According to the U.S. Census Bureau (2008), global population exceeded 6 billion in 2000, and is expected to reach 9 billion by 2050 . Conventional knowledge suggests that the growing global population will require more land on which to live and produce food for survival, and that this land requirement will come at the expense of native ecosystems as they are converted to cropland or urban living spaces (anthropogenic landscapes). This pattern has been observed in many cultures during various time periods throughout history. Today, however, we live in a world where only a small percentage of land remains relatively undisturbed. This land is found primarily in areas where agriculture, and thus human occupation, is inefficient and even impractical. Many scientists agree that these relatively undisturbed areas should be protected and conserved due to the important ecological functions they provide (Wilson et al. 2007). Although there is great pressure to support a growing population, an alternative to the conversion of our last remaining important ecosystems is needed. We suggest that one solution may be found through the integration of existing knowledge in the fields of landscape architecture and landscape ecology. This synthesis can be used to develop creative alternatives for the transformation of our anthropogenic landscapes, with a focus on multifunctionality for improving overall performance of the landscape.

The field of landscape ecology has recognized and even encouraged a connection between science and landscape design from the beginning. European 
geographer Carl Troll (1950) noted that "landscape design provides the active creation of the cultural landscape, not only to meet its functional requirements, but also to create a harmonic structure in the appearance of the landscape, if not in its artistic design." Yet a large gap remains between the growing body of research in landscape ecology and the application of this information in the design of landscapes based on ecological principles (Lovell and Johnston 2009). We suggest that a focus on multifunctionality of the landscape could help bridge this gap by offering specific design guidelines based on the goal of achieving ecological, cultural, and production functions within a given space. This approach could be applied to both agricultural and urban spaces, even combining the functions of living and producing food in the same landscape. Such an effort would require an understanding of ecosystem services provided by individual landscape elements or habitats that could enhance the quality of the entire system.

Our primary objective is to investigate the literature on the existing and potential ecological functions of different landscape features and patterns to better understand approaches for designing landscapes to improve performance. We explore landscape solutions to environmental problems by synthesizing recent developments in landscape architecture and landscape ecology. We demonstrate that multifunctionality can be more than just a condition of sustainable landscapes. It can also be a strategy for creating sustainable landscapes. In the first section, we review several important principles that could be applied to the design of anthropogenic landscapes for performance. The next section describes different landscape elements that reflect these principles and provide ecosystem services to support multifunctionality. In the third section, we explore some potential applications in urban and rural settings. The final section provides a review of different methods of evaluating and monitoring landscape performance to determine the relative success of a designed landscape. We have chosen to address urban and agricultural landscapes in the same review, because they are both intensively managed, and thus have many compatible issues. Furthermore, the research in the separate fields of agroecology and urban ecology can provide important insights that might mutually inform landscape design. It is both urban and agricultural landscapes that will fulfill the world's increasing demand for resources.

\section{LANDSCAPE ECOLOGY CONCEPTS}

The rich history of designed landscapes suggests that principles from the field of ecology can be applied not only to wilderness areas, but also to the vast lands that have been strongly influenced by human activity (i.e., urban and agricultural landscapes) (Doing 1997). Increasingly, ecologists are turning their efforts toward the interactions between humans and ecological processes in anthropogenic landscapes (Alberti 2005, Kremen and Ostfeld 2005, Liu et al. 2007). New information about the ecological value of these anthropogenic landscapes, including those supporting agriculture or residential development, suggests great opportunities for improving landscape performance in the places "where people live and work" (Miller and Hobbs 2002). Below, we briefly review several important approaches that could be used to guide the design of anthropogenic landscapes.

\section{Ecosystem services}

In the past 10 years, a greater emphasis has been placed on the specific functions provided by different ecosystems and methods for assigning value to those functions. Landscape functions provide specific services, often referred to as "ecosystem services." These can be defined as "benefits human populations derive, directly or indirectly, from ecosystem functions" (Costanza et al. 1997). Ecosystem services are classified as provisioning services (e.g., food and fodder), regulating services (e.g., climate, water, soil, and disease regulation), cultural services (e.g., education, recreation, aesthetic, and spiritual services), and supporting services (e.g., primary production and nutrient cycling) (Carpenter and Folke 2006). Early work on ecosystem services focused primarily on "natural" ecosystems. Evidence suggests, however, that humandominated landscapes, even in urbanized areas, can also provide ecosystem services. Additionally, these services have the potential to positively impact public health and quality of life for human beings not only where the services are located, but beyond their physical boundaries. Bolund and Hunhammar (1999) proposed the following services as most applicable for landscapes in urban areas: air filtering, microclimate regulation, noise reduction, rainwater drainage, sewage treatment, and recreational and cultural values. Farber et al. (2006) considered the ecosystem services of urban and 
rural long-term ecological research (LTER) sites where opportunities were recognized for both types of landscapes to provide climate regulation, biological regulation, soil retention, nutrient regulation, and aesthetic services. An effort to improve landscape performance would suggest that we should also consider the nontraditional services that could be provided by these landscapes, such as food production in urban environments, or opportunities for education in agricultural environments.

\section{Landscape multifunctionality}

The concept of landscape multifunctionality is highly informative in designing a landscape for performance. Too often, anthropogenic landscapes are manipulated to serve a single function, such as cropland for the production of food, or parks for recreation. Figure 1 illustrates how this relationship can be defined in terms of the economic, environmental, and social dimensions of the landscape. A multifunctional landscape offers opportunities to provide services in a number of realms, which may include all three of these dimensions (de Groot 2006). Multifunctionality in the context of sustainable development suggests that multiple environmental, social, and economic functions are provided by the landscape (Wiggering et al. 2003), in addition to considering the interests of landowners and land users (Otte et al. 2007). Brandt and Vejre (2004) stress the importance of focusing on "local landscapes" or "intensively used landscapes" as having the greatest potential for future work in multifunctionality. This approach suggests that we do not need to choose between the seemingly mutually exclusive goals of conservation and urbanization, but that we might design a landscape with multiple goals in mind (Gorenflo and Brandon 2005, León and Harvey 2006). Although the concept of multifunctionality related to anthropogenic landscapes has been explored in Europe and Asia, it has received limited attention in the United States, where the potential benefits are great due to the high resource use and large area of land (Groenfeldt 2006).

A related approach, termed "ecoagriculture," encourages the development of multifunctional landscapes that provide sustainable food production, biodiversity conservation, protection of ecosystem services, and poverty alleviation (McNeely and Scherr 2003). The addition of biodiversity conservation as a specific goal has important implications for ecosystem function (Vandermeer et al. 1998, Swift et al. 2004, Tscharntke et al. 2005), particularly as biodiversity and ecological heterogeneity are lost with land-use intensification (Benton et al. 2003). Building on the concept of landscape multifunctionality, the ecoagriculture approach considers the opportunity to design agricultural landscapes more creatively to improve production and ecological functions simultaneously (McNeely and Scherr 2003). Likewise, the same goals of ecoagriculture could be applied in urban settings, where we might see great benefits from the inclusion of food production functions (Hough 1983) and consideration of biodiversity conservation (Ahern et al. 2006).

\section{Landscape Structure}

The design of the landscape structure offers one of the greatest opportunities for improving landscape performance. The patch-corridor-matrix concept was developed to establish a language of landscape structure, primarily expressed through spatial pattern and arrangement. Within this model, the landscape is considered to be a mosaic consisting of three major elements. These are: "patches" of discrete areas consisting of natural or introduced vegetation differing from the surrounding landscape, "corridors" that connect and provide linkages between patches, and the "matrix," consisting of the dominant landscape type (Forman and Godron 1986, Dramstad et al. 1996). Although the patch-corridor-matrix concept has important implications for sustainable landscape planning (Blaschke 2006), these patterns may be less clear in highly fragmented anthropogenic landscapes. Recent studies suggest that instead of focusing only on large, high-quality patches and designated corridors to connect them, a better approach might be to improve the quality of the matrix in agricultural and urban landscapes (Perfecto and Vandermeer 2002, Baudry et al. 2003, Bailey 2007, Vandermeer and Lin 2008). Baudry et al. (2003) argue that "...it is now important to do more than consider habitats in a binary world that reduces a landscape to two basic categories, suitable habitats and uninhabitable matrix." Instead, we might consider landscape heterogeneity and connectivity, along with biodiversity, as good indicators of ecosystem function (Andersson 2006). Bailey (2007) recommends improving the quality of the matrix by reducing land-use intensity, increasing and 
Figure 1. Conceptual diagram of multifunctional landscape framework with economic, environmental, and social dimensions.

\section{Economic}

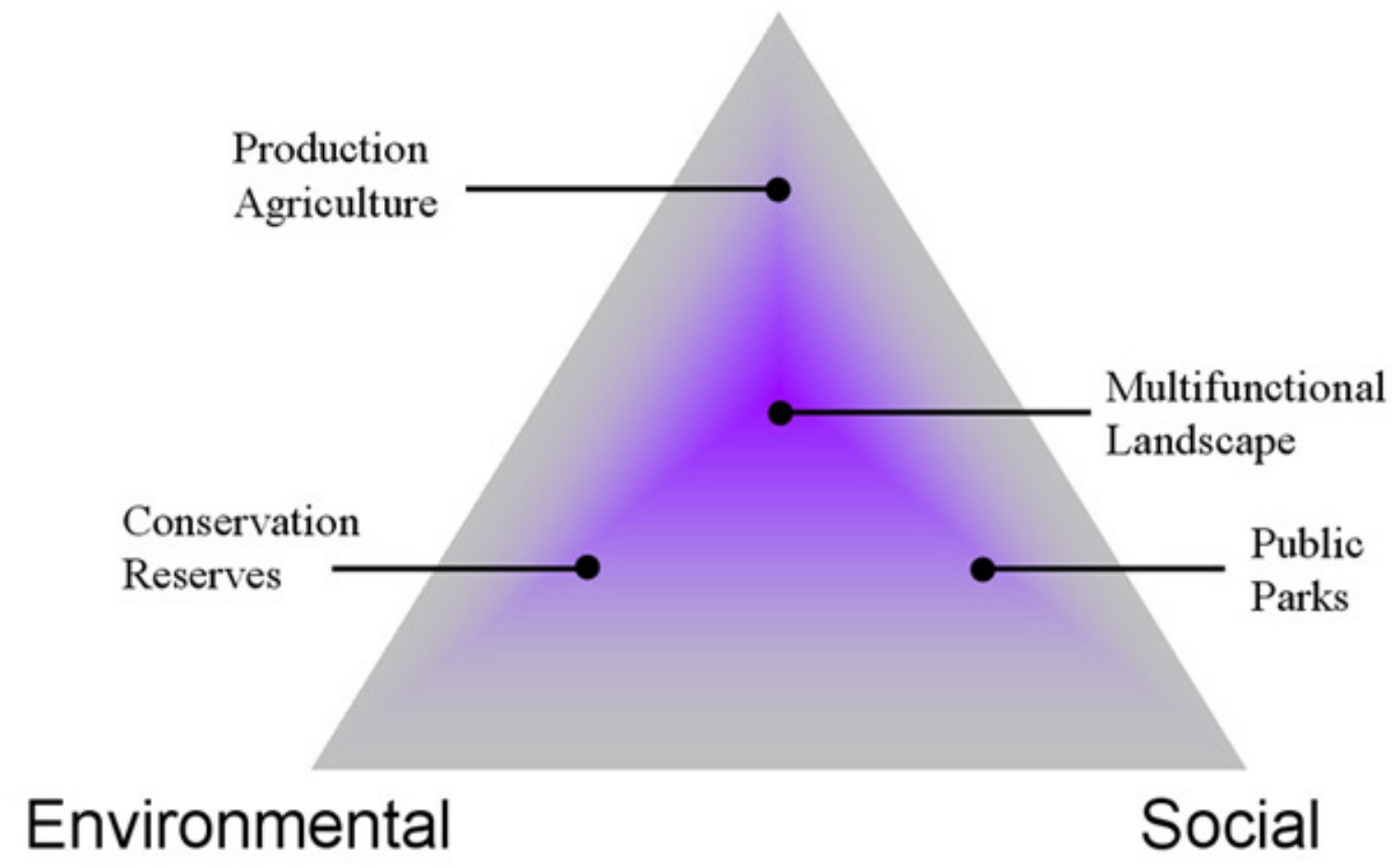

protecting seminatural habitats, and increasing overall heterogeneity. All of these could increase the connectivity of the entire landscape.

Whereas urbanization and agriculture have resulted in habitat loss and fragmentation, which threaten biodiversity through local extinction of native species (McKinney 2002), intentionally designing heterogeneity into the anthropogenic landscape pattern can improve ecosystem services in urban and rural landscapes by increasing function and resilience (Fischer et al. 2006). Benton et al. (2003) suggest that the quality of agricultural systems would be improved by the specific objective of promoting heterogeneity in the landscape as it would result in greater biodiversity in agroecosystems. Studies have shown that landscape heterogeneity and plant biodiversity can be increased in agricultural landscapes by the addition of, or conservation of, woodlots or wooded fencerows (Freemark et al. 2002), natural woody hedgerows (Boutin et al. 2002), riparian habitats (Boutin et al. 2002, Jobin et al. 2004), and live fences (León and Harvey 2006). Although non-crop landscape features typically cover only a small percentage of the area in an agroecosystem, their contribution to ecosystem services can be disproportionately large (Freemark et al. 2002, Boutin et al. 2003, Jobin et al. 2004, León and Harvey 2006). We must recognize, however, that the addition of non-crop features (which mostly benefit the public) is often considered to be a trade-off with agricultural production (which benefits private landowners), and thus requires support through publicly funded subsidies or other incentive systems (Lovell and Sullivan 2006). Urban landscapes are also very complex in terms of the relationship between landscape structure and ecosystem function 
(Andersson 2006, Cadenasso et al. 2007), but heterogeneity may contribute to the high species richness found in these settings (Wania et al. 2006). Urban habitats such as parks, cemeteries, and residential yards contribute to heterogeneity, and the design and maintenance of these spaces will have important implications for their contribution to the quality of the matrix. In both urban and agricultural settings, heterogeneity can contribute to important cultural functions, including visual quality (Angileri and Toccolini 1993, Arriaza et al. 2004, Dramstad et al. 2006), tourism, and recreation (Fleischer and Tchetchik 2005).

\section{LANDSCAPE FEATURES SUPPORTING ECOLOGICAL PRINCIPLES}

A new focus on improving matrix quality, along with other recent developments in the field of ecology (as described in the previous section), suggests that we need to consider the inherent and potential contributions of various landscape features to different ecosystem services. In Table 1, we provide a conceptualization of the cumulative value of inherent and potential services provided by a sample of landscape elements commonly found in anthropogenic landscapes. These relative levels could be replaced with direct and indirect monetary values unique to a specific setting (where data are available), since they relate to the landscape and cultural context of the region. Cumulative value is representative of relative interactions and not intended to imply a linear summation of values. Each landscape element contributes to overall performance (total value), and when designed with multifunctionality in mind, the contribution can be increased substantially. We might improve the performance and quality of a landscape by altering the spatial arrangement (configuration), plant community structure (composition), and management of those landscape features that occur frequently in anthropogenic landscapes (such as residential yards in an urban setting or field margins of an agricultural landscape). Below, we explore the ecosystem services that might be provided by different landscape features when they are designed for multifunctionality. Each of these landscape features, if designed considering configuration and composition, has the potential to contribute to a high-quality matrix.

\section{Vegetative Buffers}

Vegetative buffers are important features that exist in many different configurations in anthropogenic landscapes. In urban areas, they may take the form of linear parks, planted areas along roads, or greenways. Buffers in agricultural landscapes may take the form of hedgerows, live fences, and riparian strips located in areas that connect one patch to another, or create a network of connectivity (Lovell and Sullivan 2006). Each of these habitats can provide different functions, but they can all be designed to facilitate or regulate flows of water, resources, or certain organisms. For example, linear corridors can be important for their role in rebuilding connections that were available in the landscape before it was fragmented by development. Cultural connectivity is also important, as corridors can allow movement of people between neighborhoods of different social and economic levels (Shafer et al. 2000, Hellmund and Smith 2006). The ability of buffers to support multiple functions (including the movement of organisms) depends on their location in connecting key habitat areas (Schuller et al. 2000), their configuration in the landscape (Hellmund and Smith 2006), and the composition of plant materials. For example, studies have shown that corridors containing woody vegetation are likely to exhibit greater species richness than grassy buffers (Freemark et al. 2002, Paine and Ribic 2002, Boutin et al. 2003).

In addition to the role vegetative buffers serve as corridors, they can serve another important role in protecting sensitive areas through a variety of regulating services (Fischer et al. 2006). Extensive root systems of perennial plants in buffers hold soil in place, allow greater infiltration of water, and trap the sediment entering from adjacent areas (Lowrance et al. 2002, Lee et al. 2003). Many studies have demonstrated the effectiveness of buffers in reducing the concentration of nutrients such as nitrogen and phosphorus, as well as pesticides and other chemicals (U.S. Department of Agriculture 2000). Buffers can reduce the severity of flooding by slowing water flow and increasing the infiltration of water into soils (Schultz et al. 1997). Riparian buffers can help regulate light and temperature, creating a wide variety of habitats, and allowing wildlife access to food and water (all contributing to ecological diversity) (Naiman et al. 1993). Some evidence suggests that buffers also provide indirect environmental benefits, such as 
Table 1. Inherent and potential contributions of different design elements to different ecosystem services in intensively managed landscapes.

\begin{tabular}{|c|c|c|c|c|c|c|c|c|}
\hline \multirow[t]{3}{*}{ Landscape Features } & \multicolumn{6}{|c|}{ Ecosystem Services } & \multirow{2}{*}{\multicolumn{2}{|c|}{$\frac{\text { Total }}{\text { Performance }}$}} \\
\hline & \multicolumn{2}{|c|}{ Provisioning } & \multicolumn{2}{|c|}{ Regulating } & \multicolumn{2}{|c|}{ Cultural } & & \\
\hline & $I^{*}$ & $\mathrm{P}^{* *}$ & I & $\mathrm{P}$ & I & $\mathrm{P}$ & I & $\mathrm{P}$ \\
\hline Patches of native vegetation & $\mathrm{n}^{* * *}$ & $\$ \$$ & $\$ \$$ & $\$ \$ \$$ & $\$$ & $\$ \$$ & $\$ \$ \$$ & $\$ \$ \$ \$ \$ \$ \$$ \\
\hline Vegetative buffers & $\mathrm{n}$ & $\$ \$$ & $\$ \$ \$$ & $\$ \$ \$$ & $\mathrm{n}$ & $\$ \$$ & $\$ \$ \$$ & $\$ \$ \$ \$ \$ \$$ \\
\hline Natural or constructed wetlands & $\mathrm{n}$ & $\$ \$$ & $\$ \$ \$$ & $\$ \$ \$$ & $\$$ & $\$ \$ \$$ & $\$ \$ \$$ & $\$ \$ \$ \$ \$ \$ \$ \$$ \\
\hline Edible gardens & $\$ \$ \$$ & $\$ \$ \$$ & $\$$ & $\$ \$$ & $\$$ & $\$ \$ \$$ & $\$ \$ \$ \$$ & $\$ \$ \$ \$ \$ \$ \$$ \\
\hline Stormwater infiltration systems & $\mathrm{n}$ & $\$ \$$ & $\$ \$ \$$ & $\$ \$ \$$ & $\mathrm{n}$ & $\$ \$$ & $\$ \$ \$$ & $\$ \$ \$ \$ \$ \$ \$$ \\
\hline Waste treatment systems & $\mathrm{n}$ & $\$ \$$ & $\$ \$$ & $\$ \$ \$$ & $\$$ & $\$ \$$ & $\$ \$ \$$ & $\$ \$ \$ \$ \$ \$ \$$ \\
\hline
\end{tabular}

These relative contributions are presented from a conceptual perspective, but they could be replaced with direct and indirect monetary values where data are available for a given region.

$* \mathrm{I}=$ the relative inherent value typically provided by these landscape features for each category of ecosystem service

$* * \mathrm{P}=$ the relative potential value these landscape features could provide if designed using the landscape multifunctionality approach

$* * *$ Relative values are indicated by: $\mathrm{n}=$ none; $\$=$ low; $\$ \$=$ medium, and $\$ \$ \$=$ high

increasing the biodiversity of flora and fauna, and providing habitat for wildlife (Schultz et al. 1997) by allowing safe movement between fragmented patches of natural areas (Schuller et al. 2000). Buffers with trees can provide additional functions including filtering polluted air, mitigating unpleasant odors (Tyndall and Colletti 2001), reducing noise (Thompson and Sorvig 2000), and regulating the microclimate with their shade (Bolund and Hunhammar 1999).

\section{Natural and Constructed Wetlands}

Wetlands (both natural and constructed) are multifunctional habitats that can be incorporated into the landscape pattern to provide regulating services. Of all terrestrial biomes, natural wetlands have the highest value for ecosystem services, primarily due to their ability to moderate disturbances (most notably, flooding), treat waste, and supply water (Costanza et al. 1997). Wetlands store, cleanse, and infiltrate water from upstream, contributing to the cycle of recharge of the groundwater supply. Plants in wetlands contribute to nutrient cycling and detoxification of nutrients. These are important processes for treating sewage and other waste (Bolund and Hunhammar 1999, Mitsch et al. 2001). Wetlands serve important habitat functions due to the rich diversity of flora and fauna resulting from unique conditions of a wetdry cycle (Mitsch and Gosselink 2000). A number of reptiles and waterfowl rely upon natural wetlands as permanent habitat or migration corridors (Poor 1999, Roe and Georges 2007). Recent interest in environmental health at the global scale highlights 
the role of wetlands in contributing to carbon sequestration and climate regulation (Mitsch and Gosselink 2000). Wetlands also contribute to important cultural functions including recreation (both consumptive and nonconsumptive), visual quality, and cultural heritage values, as reflected by an often positive impact of nearby wetlands on property values in urban and sometimes rural areas (Boyer and Polasky 2004). Wetlands can also directly support provisioning services including habitat for fish and shellfish for commercial harvest, a supply of water for irrigation of terrestrial crops (Boyer and Polasky 2004), and the production of harvestable vegetative materials including peat and sphagnum moss, wild rice, and cranberries (Mitsch and Gosselink 2000).

Landscapes can be designed to preserve existing wetlands, restore previous wetlands, and incorporate new constructed wetlands to improve performance. Due to the high value of ecosystem services provided by natural wetlands, every effort should be made to protect these features from disturbance from anthropogenic activities in the design of the landscape. In areas where wetlands have been drained or filled to support agriculture or other anthropogenic activities, design projects can focus on restoring the functional capacity of the previous wetland by removing the artificial drainage system, reshaping the topography, and establishing appropriate plant communities. Constructed wetlands can be designed into almost any site for the treatment of polluted water. Whereas constructed wetlands are often designed for the treatment of waste water, they are also effective in treating polluted stormwater from roads and lawns before it enters a lake or stream. These landscape features have been shown to remove suspended solids, nutrients, bacteria, and heavy metals from urban runoff (Mungasavalli and Viraraghavan 2006).

\section{Edible Gardens}

Kitchen gardens have long been used for the production of food near the house. Residential yards in urban or agricultural settings today can still include areas for the production of food or other crops, contributing to urban agriculture. Urban agriculture is common in developing countries, and in some developed countries during times of war when starvation is a realistic threat. Urban agriculture can provide important environmental benefits in a city because it reduces the energy required to transport food to the consumer, and decreases waste due to composting and a reduction in packaging materials. This approach also contributes to important social functions such as the physical benefits of working in a garden (Doron 2005) and psychological benefits including stress recovery and mental restoration resulting from views of nature in proximity to the home (Kaplan 2001, Hellmund and Smith 2006). In the case of community gardens or community farms, areas might be set aside in a common public space to support production functions through the growth of edible and ornamental plants (used to feed local residents or to sell for income) (Fig. 2). This function can be particularly important for residents in lowincome areas, where access to healthy, fresh food might be limited (Franco et al. 2008). Providing access to nutritious food could result in direct financial benefits, in terms of reducing health care costs related to diabetes, obesity, and other chronic diseases (World Health Organization 2003). The inclusion of a production element in environments that are primarily residential can increase efficiency in food processing, reduce transportation costs, and provide educational opportunities by linking people with food systems. Community gardens can also serve an important social role by bringing individuals together in a community setting and by encouraging outdoor exercise.

\section{Stormwater Infiltration Systems}

The impervious surfaces that accompany most anthropogenic developments result in an increase in the stormwater runoff from these sites. Often, this stormwater runoff contains harmful pollutants (including heavy metals, suspended solids, nutrients, and bacteria) that contaminate nearby surface water. Stormwater infiltration systems are used to capture, infiltrate, and treat some portion of the runoff, reducing the negative impact of development on aquatic ecosystems. These features can be designed into the landscape to provide a wide range of additional ecological functions (such as microclimate control, wildlife habitat, and biodiversity), as well as cultural functions (including education and visual quality) (Dunnett and Clayden 2007). Most of the systems are developed as shallow trenches or basins containing a porous medium (such as sand, gravel, or organic matter) that allows infiltration. Although a number 
Figure 2. Community garden for the production of food and flowers.

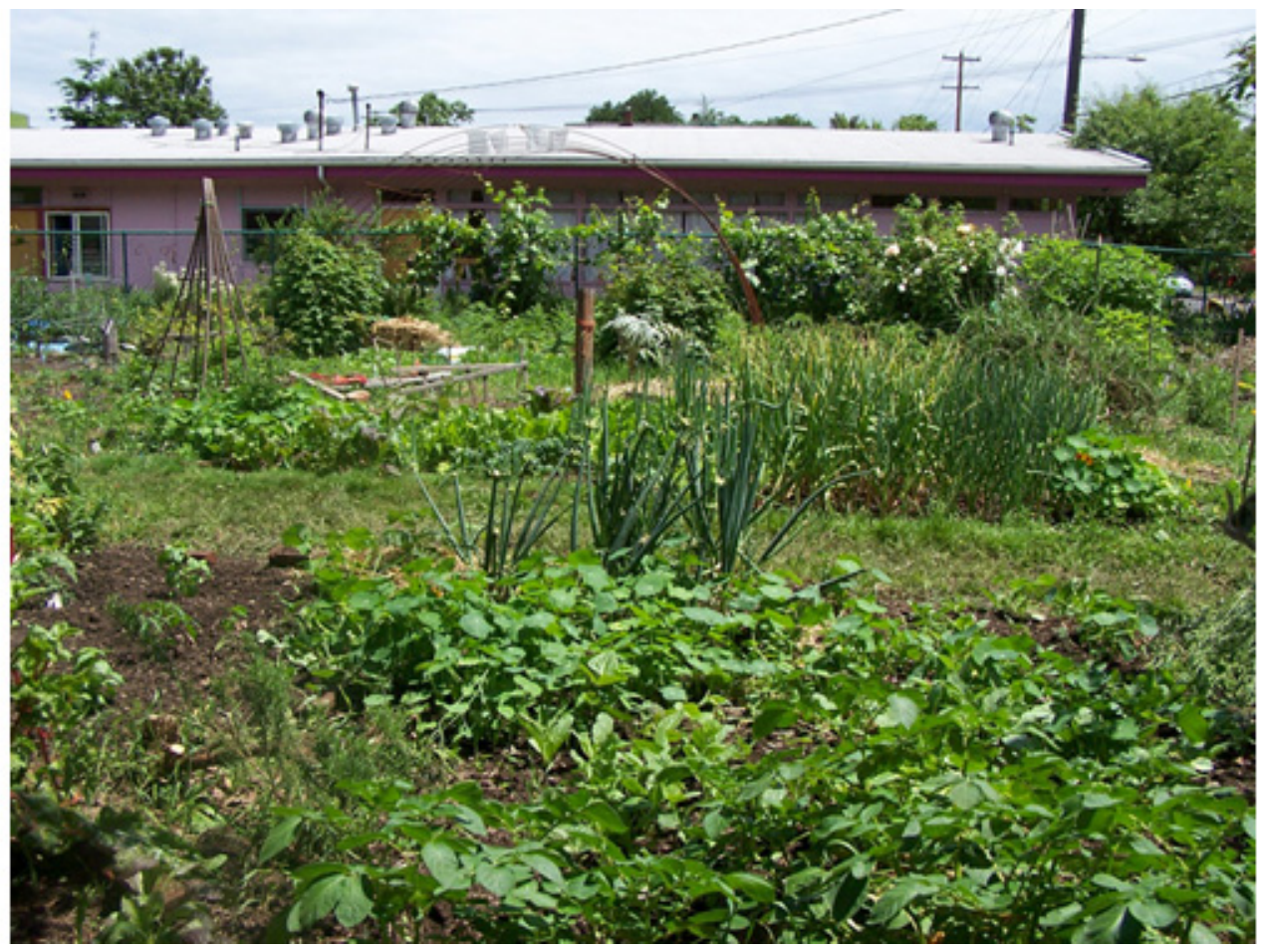

of different types of designs exist for large-scale stormwater treatment in detention or retention basins, small-scale stormwater infiltration systems (Fig. 3) typically take the form of "bioswales" (shallow ditches often used along edges of parking lots), rain gardens (planted depressions accepting runoff from a building), or green roofs (rooftops covered with vegetation and a supportive substrate) (City of Portland 2004, Oberndorfer et al. 2007). Although these features are primarily designed to support regulating services (i.e., water control), the potential also exists to support production functions through the growth of woody biomass for energy, or cultural functions through the provision of visual quality and recreation.

\section{Waste Treatment Systems}

Other landscape features that are rarely considered for their positive functions are the treatment systems for human, animal, and industrial waste. Although these are typically criticized for their unpleasant odor and appearance, waste treatment systems serve as a repository for heat and nutrient resources that might support biodiversity and agricultural production (Hough 1983). John Todd and his colleagues have proposed and designed a number of ecologically engineered systems to treat, recycle, and reuse wastewater, both in built structures and in the landscape (Todd et al. 2003). In addition to providing ecological and production functions, these specialized features can provide important research and education functions (Hough 1983).

\section{LANDSCAPE APPLICATIONS AND OPPORTUNITIES}

Vegetative buffers, natural and constructed wetlands, edible gardens, stormwater infiltration systems, and waste treatment systems are just a few of the landscape features that can be incorporated into the design of the landscape. Such landscape features offer unique opportunities for improving 
Figure 3. A raingarden that is designed to treat and infiltrate stormwater from the rooftop and parking lot of Mount Tabor Middle School in Portland, Oregon, also serves an educational function.

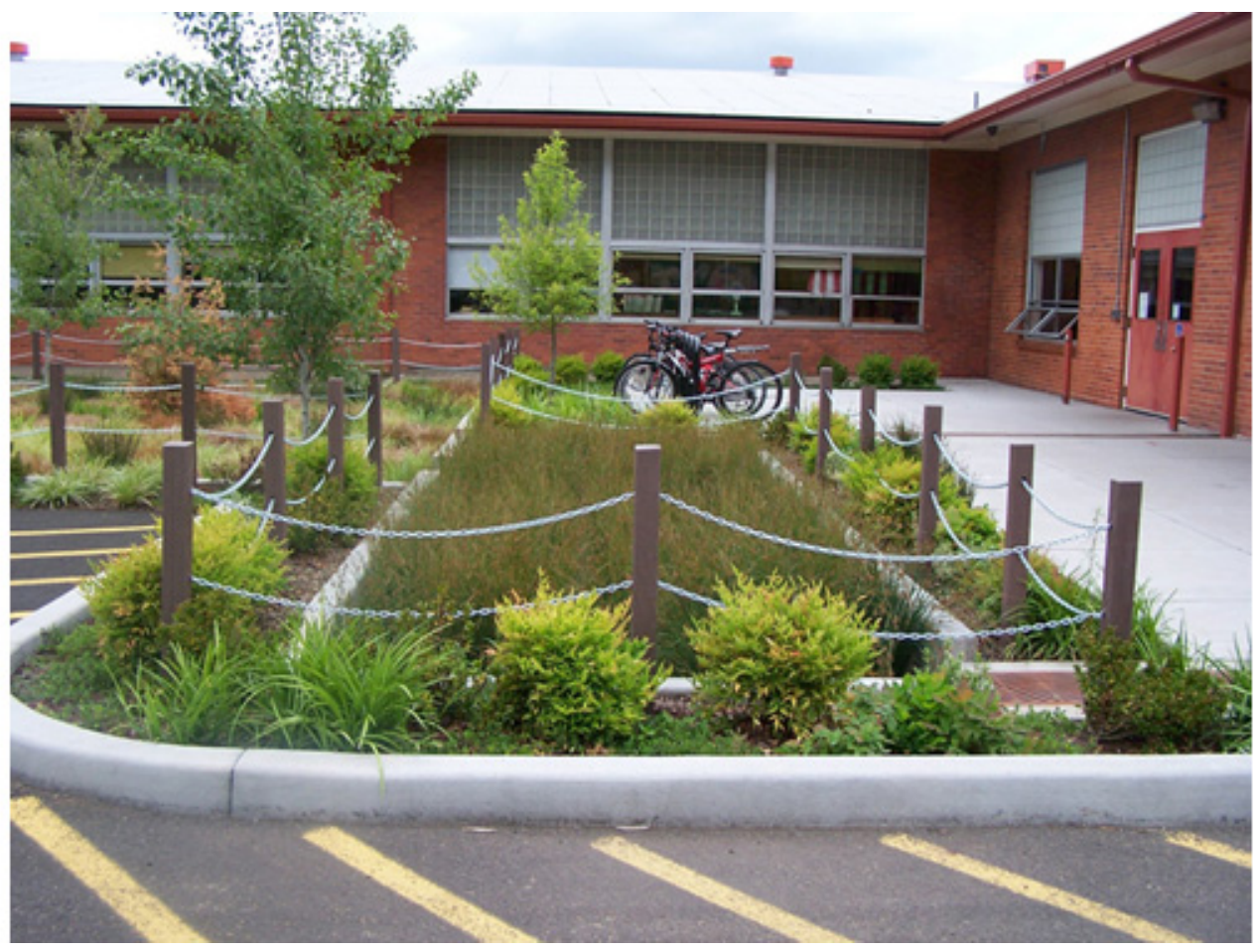

performance. Below, we explore several applications of these and other features that could greatly impact the health of landscapes and the communities that depend on them within urban and agricultural environments.

\section{Residential yards}

Residential yards (also referred to as domestic gardens) include mowed lawns, ornamental flower beds, vegetable beds, hard paths, trees, and outdoor walls. These sites are among the largest contributors to urban green space, making up $19 \%-27 \%$ of the urban area in UK cities (Smith et al. 2005), for example. However, the ability of residential yards to contribute to ecological functions depends on their composition and configuration, as well as their size. A study of domestic gardens in Sheffield, UK, demonstrated that large gardens contribute more to ecosystem services than small gardens, due to a greater number of land-cover types, disproportionately greater canopy cover, and less area in sealed surfaces (Smith et al. 2005). Nonetheless, smaller gardens can be important due to the large numbers that exist in urban areas (Gaston et al. 2005, Loram et al. 2007). Residential yards can serve important functions for the conservation of biodiversity and the provision of ecosystem services because they provide connected and integrated green space in a city (Loram et al. 2007). Residential yards are such an extensive feature of most fragmented landscapes that modifying them based on multifunctionality could have great impacts in coming years.

With creative design, residential yards can support a wide range of ecological functions including wildlife habitat, stormwater infiltration, carbon sequestration, microclimate regulation, and nutrient cycling (Thompson and Sorvig 2000, Smith et al. 2005). For example, to serve a stormwater infiltration function, the area might be designed with rain gardens and bioswales, and also be managed to minimize soil compaction and erosion. Designing 
landscapes with a plant community structure will increase biodiversity and improve the supporting services of the landscape, compared with those found in many conventional designs. A simple example of a site-level opportunity for improving biodiversity in a residential area is the replacement of a conventional turf lawn with a mix of prairie species (Diekelmann and Schuster 2002). The vertical structure of vegetation in these relatively small, but intensively managed, spaces may offer one of the greatest and most unique opportunities to increase the functional area of vegetation. Vertical elements include single mature trees with large canopies, tree groupings, shrub plantings, and even vines growing on a trellis or another structure (Smith et al. 2005). This additional vegetation can reduce airborne pollution, moderate the local climate, diminish noise (Bolund and Hunhammar 1999), and even provide healthy food (Jacke and Toensmeier 2005), as shown in Fig. 4. In addition to providing ecological functions, residential yards can also support production and cultural functions, through the addition of edible gardens that provide healthy food and recreation.

\section{Contaminated Sites}

"Brownfields" are polluted or contaminated sites formerly used for industrial or commercial purposes, where redevelopment opportunities are limited by the potential hazards posed to future users. However, brownfields can be candidates for landscape rehabilitation, with potential reuse as recreational areas or nature preserves, enhancing the ecological functioning of the landscape (De Sousa 2003, Burger 2005, Levi and Kocher 2006). The conversion of brownfields into parks and other public green spaces has recently become a more widely accepted rehabilitation opportunity for landscape designers. Many of these projects are subsidized through various funding organizations including the US Environmental Protection Agency - One noteworthy project that includes both ecological and cultural functions is Emscher Park in Germany, an $800 \mathrm{~km}^{2}$ site that is undergoing redevelopment through over 100 separate projects on a brownfield where steel and coal industries previously existed. The projects include the preservation and reuse of the huge industrial structures (steel plants, smoke stacks, and storage tanks) as "industrial monuments" to support new cultural activities and events. This project demonstrates that brownfield rehabilitation can result in a multifunctional landscape, providing important regulating and cultural services. However, although many excellent rehabilitation opportunities exist with brownfields, they must be balanced by the potential risk to human health associated with a contaminated site (Greenberg and Lewis 2000).

\section{Public Green Spaces}

Public green spaces exist in urban and agricultural landscapes and may include parks, nature reserves, college campuses, public schools, cemeteries, and research farms. As they currently exist, these features often serve multiple functions. For example, parks are specifically designed for recreation, but they are also known to provide a range of other ecosystem services including microclimate regulation, air quality control, stormwater management, and wildlife habitat (Jim and Chen 2006a). These spaces increase the quality of life for urban residents by providing both social and psychological services, including stress reduction, support for recovery from illness, and a location that fosters the development of social ties (Chiesura 2004). The high social value of the cultural functions offered by urban green spaces is often reflected by an increase in the economic value of the real estate surrounding such areas (Tajima 2003) and the willingness of individuals to pay to use these spaces (Jim and Chen 2006b).

Public green spaces offer excellent design opportunities because of the existing and potential functions they are able to provide. At the landscape scale, planners and designers should consider opportunities to conserve existing public green spaces, protect and even expand these spaces with buffers or other green spaces on adjacent private lands, and connect these features with green public corridors. "Greenways" are a special type of corridor designed to accommodate multiple functions such as biodiversity conservation, stormwater management, recreation, and visual quality (Hellmund and Smith 2006). Greenways might also be designed to accommodate production functions, by incorporating plant materials that provide hay from grasses and legumes, timber sawn from hardwood trees, and nuts or berries from various fruiting species (Schoeneberger et al. 2001). Continuous productive urban landscapes (CPULs) have been proposed as an innovative design 
Figure 4. A grapevine arbor in a residential yard provides shade as well as an edible product for the homeowners.

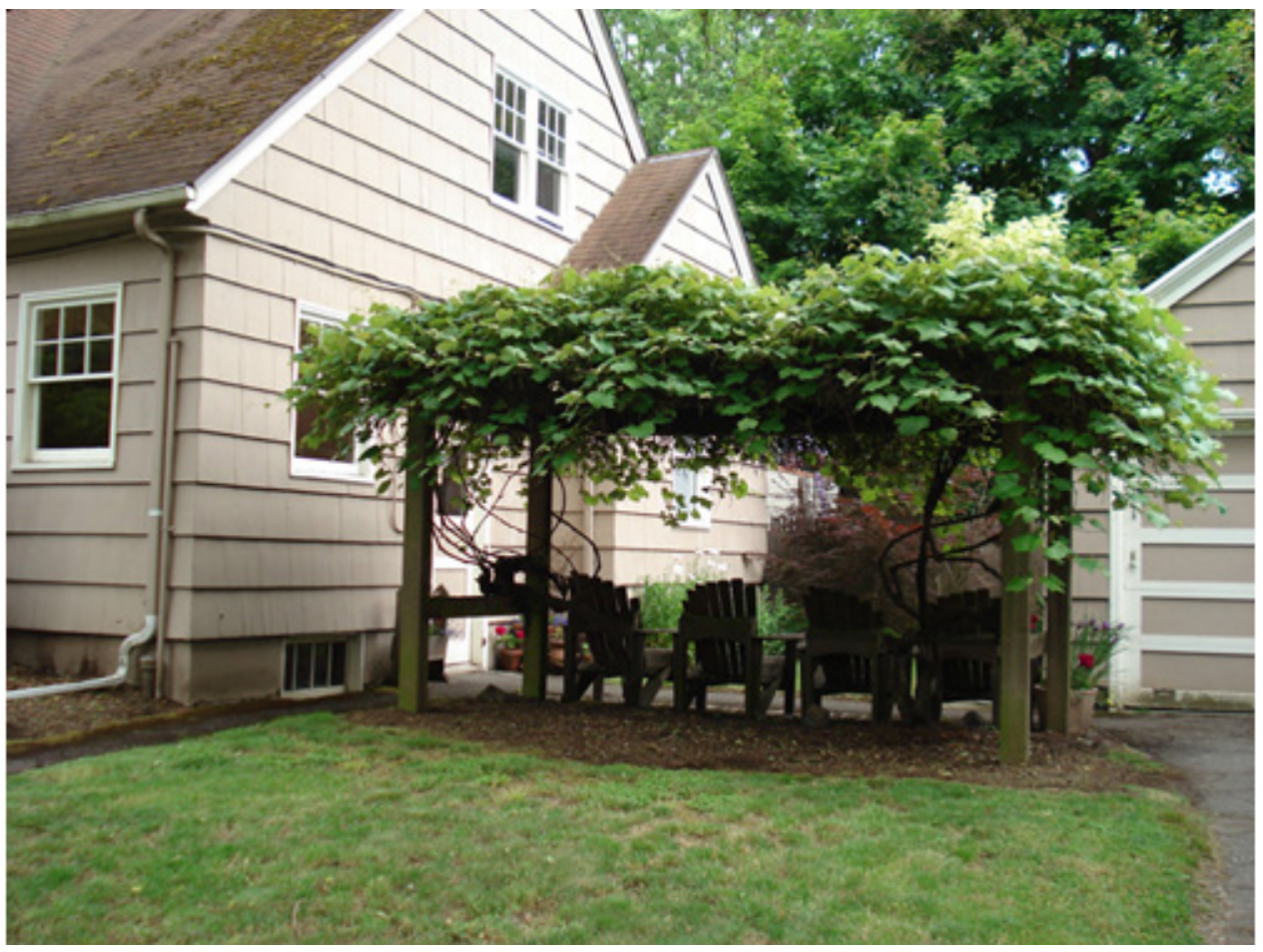

approach, using agricultural corridors to connect other vegetative patches in urban environments (Viljoen 2005).

In addition to considering design at a landscape scale in terms of increasing multifunctionality, opportunities also exist at the site scale to improve conventional functions and incorporate unconventional functions into public spaces. Conventional cultural services such as recreation, human health, aesthetic quality, and education can be enhanced by supporting a variety of plant communities (Jackson 2003). Examples include native forests and prairies for wildlife viewing and bird watching, open turf for team sports, and savanna settings for picnicking. The visual quality of a landscape can be improved through planting designs that include preferred features such as trees and water (Kaplan and Kaplan 1989) and screening of unpleasant views (i.e., highways or landfills). Landscapes containing areas of native plant communities, or historical collections, can provide a wide range of educational and research opportunities. Unconventional ecological and production functions should also be considered for public green spaces. Stormwater infiltration, air pollution control, and waste treatment are functions that can be incorporated to improve the environment and provide educational opportunities. Figure 5 shows a multifunctional space located amidst the residential dormitory buildings at the University of Vermont, where stormwater treatment is integrated with a small outdoor amphitheater. Other public sites such as schoolyards might be designed to support cultural functions specific to children, by providing adequate space and landscape diversity to encourage active play (Ozdemir and Yilmaz 2008), along with educational gardens to teach children about ecological functions or food production (McAleese and Rankin 2007). 
Figure 5. Multifunctional stormwater treatment feature in the residential dormitory green space at the University of Vermont.

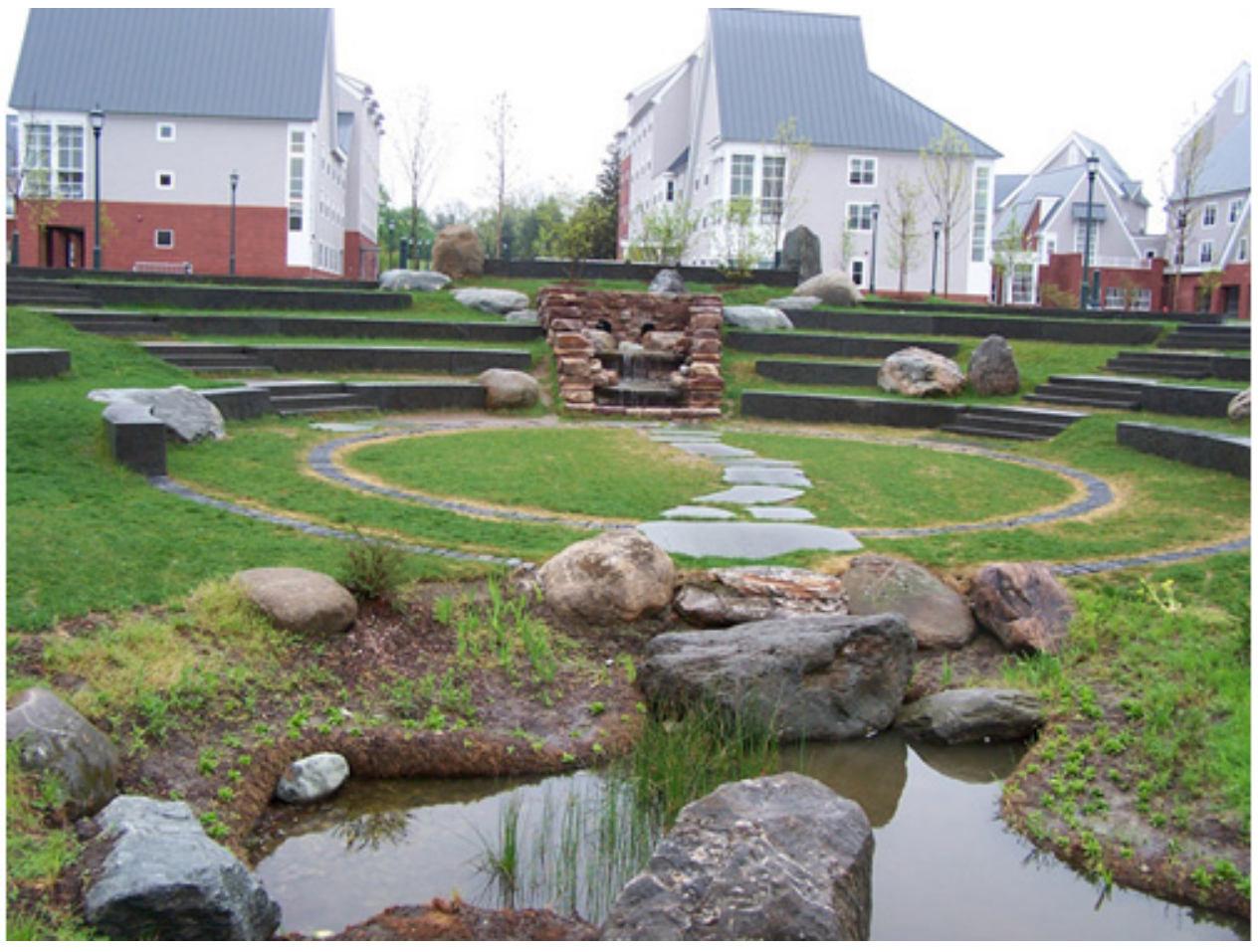

\section{Transportation Infrastructure}

Transportation infrastructure includes roads, pathways, parking lots, and other features that support vehicular and pedestrian movement. These features impact ecosystem functions to varying degrees, depending on the area covered, materials used, and their arrangement on the landscape. These built landscape features are primarily criticized for their negative impact on ecosystem health. For example, habitat functions are affected by roads, which cause impacts such as fragmentation, the isolation of populations, the spread of invasive species, and songbirds' avoidance of an area (Forman and Alexander 1998). However, landscapes can be designed to minimize these negative impacts and potentially improve ecosystem services. The most important design approaches to the transportation system may be to create efficiencies in road infrastructure that reduce the impacted area, and to avoid construction of new roads on, or near, sensitive ecosystems whenever possible. Traffic volumes can be reduced by offering alternative transportation systems such as public transportation on a light-rail system and greenway trails for safe bike or pedestrian movement (Shafer et al. 2000).

Where transportation infrastructure is necessary, specific measures can be taken to reduce the impacts to the surrounding environment. The impervious surfaces associated with many roads and parking lots can cause rapid runoff and erosion in ditches following rain events. Pollutants from vehicles on the road and from chemicals applied to the roadside vegetation can enter streams, reducing water quality (Forman and Alexander 1998). The area of impervious surface can be reduced through innovative technologies and creative designs that combine uses, such as a bike path along a vehicular transportation route. The use of permeable pavements on roads, pathways, and parking lots can allow infiltration or storage of stormwater, reducing the negative impacts of these features on the 
regulation of water quality and quantity. Buffers and bioswales introduced along transportation features can filter contaminated runoff before it enters streams (Fig. 6). These and other features offer opportunities to increase the biodiversity within the roadside right-of-way (ROW) through the addition of street trees and other perennial species along urban transportation systems. The ROW could potentially serve as a source of biofuel, if energygenerating crops are grown in this underutilized space. Transportation systems can also be designed to support more cultural functions by providing safe and aesthetically appealing spaces for walking to improve human health (Frank et al. 2004).

\section{Built Structures}

Like transportation systems, built structures are typically viewed as landscape features that negatively impact the environment. However, they are obviously necessary features for providing shelter in most climates, and can be designed to reduce negative impacts and even provide some ecosystem services. For example, buildings and their immediate environment can be developed to optimize climate regulation (Shashua-Bar et al. 2006). Many types of vegetative landscapes surrounding buildings can provide favorable microclimates, moderating temperatures through shading and reflectivity. Hardscapes typically result in less favorable climates, as dark-colored pavement contributes to the "heat island effect," significantly increasing temperatures in the surrounding environment. This problem can be minimized by reducing the amount of pavement and selecting materials with greater reflectiveness or "albedo" (Thompson and Sorvig 2000). Street trees and built features such as overhangs can be included in designs of human-dominated landscapes for microclimate control (temperature moderation and windspeed reduction), resulting in a decrease in the total energy requirements for heating and cooling buildings, while also reducing carbon emissions (Jo and McPherson 2001).

Other specialized built features can be intentionally designed to provide important regulating services. Rooftops designed with the technology to support vegetation growth (green roofs) can serve functions of infiltration, microclimate regulation, recreation, and even food production (Oberndorfer et al. 2007). Green roofs are typically used to provide some storage of stormwater, a portion of which is taken up by plants or evaporated from the surface before entering the storm sewer (Earth Pledge 2005). A study by Saiz et al. (2006) demonstrated that green roofs serve a climate regulation function due to low solar absorbance and insulation of the buildings they cover. Green roofs also moderate heat flux through evapotranspiration and physical shading, reducing the costs associated with cooling the building (Oberndorfer et al. 2007). More research is needed to develop a better understanding of the extent to which green roofs might contribute to provisioning services (such as the production of herbs or other food crops for restaurants) and cultural services (including urban aesthetics, recreation, and education). A simple alternative to green roofs is to collect rainwater from the rooftop gutters and use the water to irrigate the nearby landscape (Fig. 7).

\section{LANDSCAPE ANALYSIS}

Although we can develop design guidelines recommending the configuration and composition of various landscape features for a generic site, Aldo Leopold (1933) has suggested that we observe and experiment to decide what is appropriate for the design of a specific landscape. If landscapes are to be designed with the intention of increasing performance, methods are needed to assess and monitor the success in meeting these goals. A number of different experimental approaches have been proposed for measuring the success of anthropogenic landscapes, and for improving our understanding of the role of humans in these ecosystems. Below, we review several approaches that might be employed in the study of multifunctional landscapes for improving performance.

\section{Comparative Analysis}

Comparative analysis can be useful as an experimental approach in the study of large and intensively managed landscapes where replication and manipulation of the environment are not appropriate. This analysis does not require modification of the environment, and instead of replication, it relies on the development of correlations for the comparison of multiple locations based on implicit trends or patterns in different variables. Comparative analysis has been used to study patterns of deforestation, land-use 
Figure 6. Raingardens developed between streets and sidewalks infiltrate stormwater from these impervious surfaces, while also supporting diversity in vegetation.

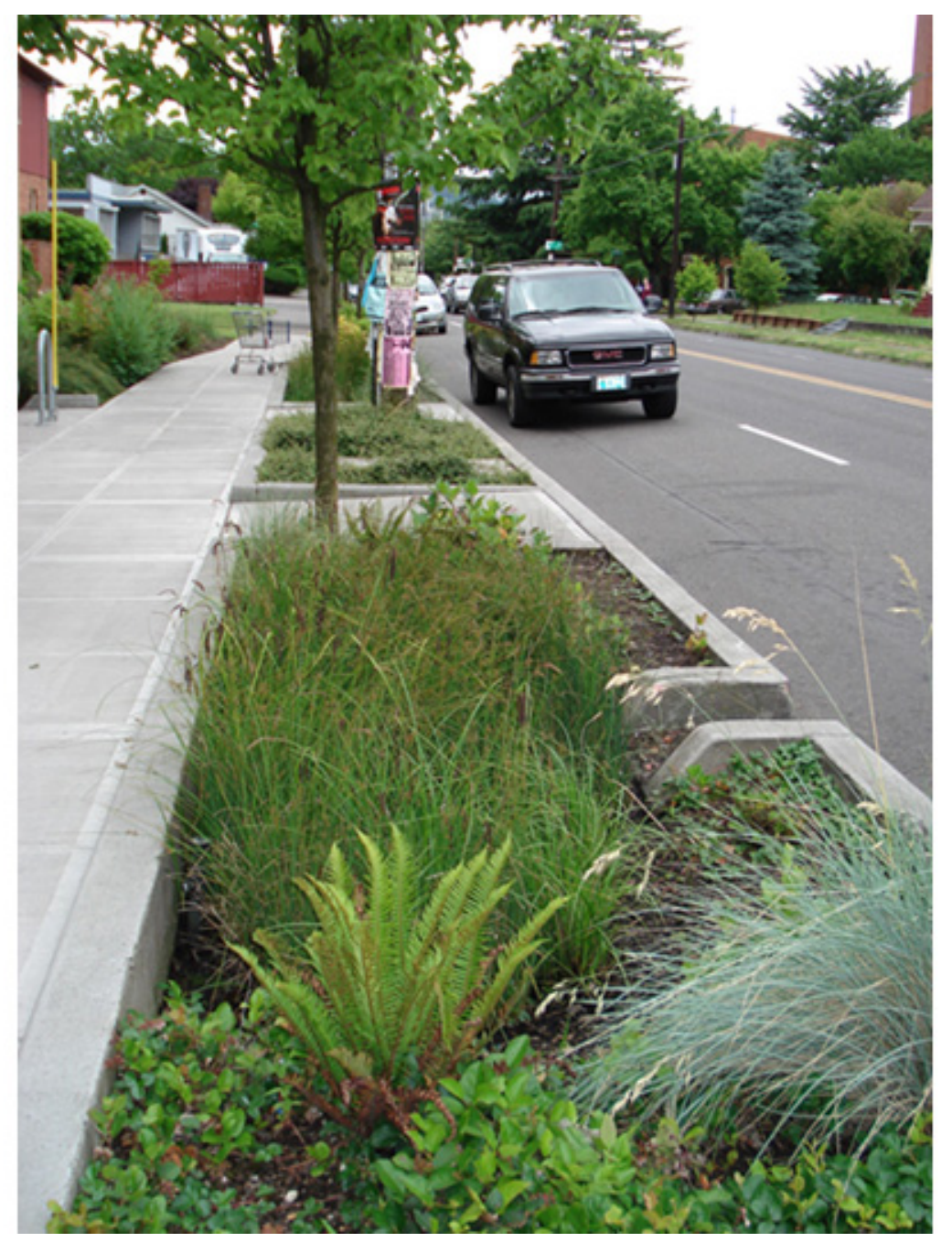

change (Seto and Fragkias 2005), population density (Kasanko et al. 2006), biodiversity restoration (Nordlind and Ostlund 2003), and many other variables. Comparative analysis can also be effective in assessing the impact of policy and planning decisions on the implementation of alternative spatial structures. Erickson (2004), for example, compared the historical context, institutional structures, and spatial patterns of two cities to develop a better understanding of the factors underlying the implementation of greenway systems. A number of organizing strategies have been used to improve comparative analysis techniques. Studies across a rural-urban gradient can be used to demonstrate changes in plant composition and ecosystem health along a transect (McDonnell et al. 1997). Pickett et al. (1997) proposed the use of comparative studies of ecosystems with a watershed approach as the spatial basis for organization in studying urban ecosystems. The watershed is a land unit that not only reflects many hydrologic, ecological, and geological features, but has also played an organizing role in urban development (Pickett et al. 1997). In addition to the spatial component of comparative landscape analysis, a temporal dimension is often included in 
Figure 7. Rainwater from a rooftop is diverted to nearby gardens to support vegetation. This feature also serves an aesthetic function as rainwater creates a waterfall.

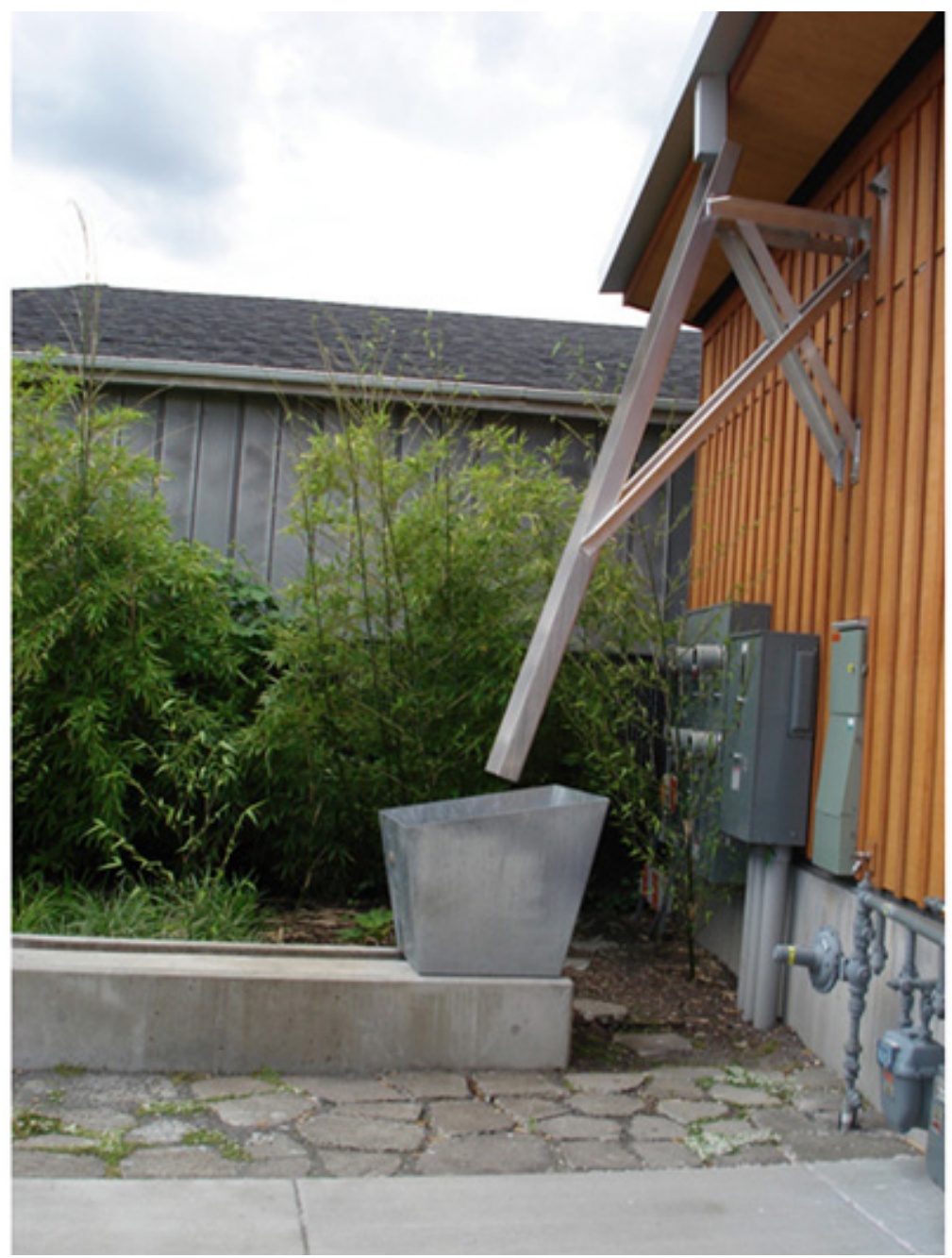

the analysis to characterize the status and change of important ecosystems (Laacke 1995). Geographic information systems (GIS) have greatly enhanced the ability to analyze landscapes in both spatial and temporal dimensions (Aschenwald et al. 2001, Smith et al. 2003).

\section{Adaptive Experimentation}

Adaptive experimentation is a research approach that "...balances traditional reduction experimental design...with the incorporation of realistic system complexity and consideration of the ethical concerns that arise when studying humans" (Cook et al. 2004, p. 469). It provides an opportunity to combine ecological and social science research in long-term experimental manipulations, including human and nonhuman feedbacks. As an adaptive approach, the treatments and hypotheses may be altered during the course of the experiment, depending on the changing conditions characteristic of a real-world situation. The experimental design is still considered to be statistically rigorous and reproducible, depending on the use of replication and controls (Cook et al. 2004). Studies using this 
approach have been initiated at the Central ArizonaPhoenix long-term ecological research program to compare different residential yard treatments based on ecological variables (i.e., soil microbes and animal biodiversity) and social variables (i.e., water use and landscape behavior). As an extension of adaptive experimentation, Felson and Pickett (2005) proposed the use of "designed experiments" that link ecological research with urban design in a replicated and rigorous analysis to compare different landscape elements or functions with a limited number of quantifiable variables. An example would be the implementation of two different approaches to the design of a subdivision. One approach would be a traditional subdivision that serves as a control, and the other would be an experimental subdivision that employs bestmanagement practices, including cluster development. In addition to the benefit of providing quantifiable data, these designed experiments offer opportunities for education, ecological functions, and aesthetic quality.

Because adaptive and designed experiments have been specifically developed to account for the uncertainty inherent in anthropogenic landscapes, these approaches could be very appropriate for assessing the performance of multifunctional landscapes. These experimental approaches could be used to test a wide range of strategies for improving the performance of anthropogenic landscapes, including the replacement of conventional turf yards with diverse plant communities, phytoremediation of brownfields, integration of production functions into public green spaces, treatment of contaminated stormwater through bioinfiltration beds, and many others. In all cases, such strategies can be designed into the landscape as experiments, and they can (and arguably, should) adapt to the changing conditions inherent in a human-dominated systems. To facilitate data gathering, infrastructure for monitoring could be incorporated directly into the design of the landscape. De Blust and van Olmen (2003) have called for a transdisciplinary approach to monitoring multifunctional landscapes including ecological, economic, and social data.

\section{Landscape Scenarios}

The development of landscape scenarios can be a valuable tool that allows stakeholders to visualize and assess future landscape alternatives, based on the established relationships between landscape patterns and different functions. Scenarios are developed from specific conditions and assumptions defined by stakeholders and experts to deal with the uncertainty of future landscape changes through a structured approach (Peterson et al. 2003). Often, the models are based on expected future landscape patterns (Wollenberg et al. 2000). However, Nassauer and Corry (2004) have proposed the use of normative landscape scenarios that reveal new trajectories for "desirable" (yet plausible) future landscape patterns based on expert knowledge of ecological function. One goal of this approach is to encourage stakeholders to consider new alternatives that inspire policy initiatives to support these desired landscape futures. The process of developing normative scenarios involves the collection of existing and new data on the site, as well as the formulation and testing of hypotheses based on plausible assumptions. The scenarios can be represented through a wide range of media, including maps, visual simulations, and threedimensional models (Daniel and Meitner 2001, Pullar and Tidey 2001, Tress and Tress 2003, Santelmann et al. 2006). This approach has important applications for assessing landscape multifunctionality as it allows stakeholders to compare the performance of different landscape futures based on ecological, cultural, and economic functions. An example is the comparison of scenario-based goals that emphasize agricultural production, water quality, or biodiversity, with a multifunctional scenario focusing on opportunities to encourage these functions simultaneously (Nassauer and Corry 2004). The valuation of ecosystem services may be employed as a strategy for comparing the performance of different landscape alternatives. This approach relies on direct and indirect measures to quantify the monetary value of provisioning, regulating, and cultural services (Carpenter and Folke 2006, de Groot 2006). Figure 8 demonstrates how the cumulative value of different types of ecosystem services (whether direct or indirect) leads to an assessment of overall landscape performance.

\section{CONCLUSION}

We have reviewed recent developments in the field of ecology for their applications in the design of anthropogenic landscapes. We have focused on ecosystem services and multifunctional landscape 
Figure 8. Conceptual diagram of the landscape performance model.

\section{Value of Multifunctional Landscapes}

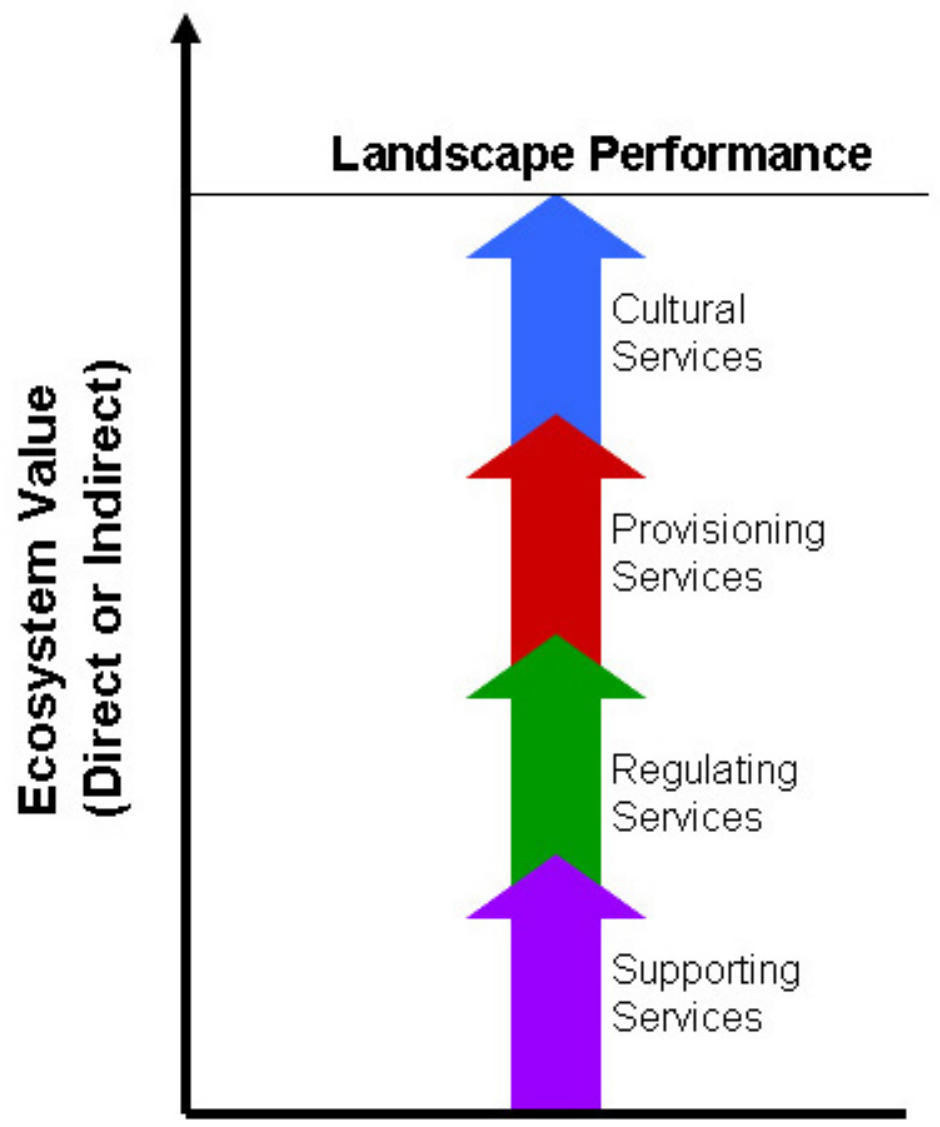

approaches that contribute in a significant and complementary way to our understanding of the performance of urban and agricultural landscapes. These approaches have important applications for designing anthropogenic landscapes, simultaneously considering economic, environmental, and cultural goals. Perhaps the most interesting finding in this review was the very wide range of studies demonstrating opportunities for individual landscape elements to provide important ecosystem services. Taken alone, these individual elements might not appear to have a large impact on the environment, but when considered together within the entire landscape, the contribution could be significant, particularly when these elements are intentionally designed to improve landscape performance. Previously, much attention has focused on the value of large patches of native vegetation for conservation efforts, attempting to preserve those that still remain, restore those that once existed, and provide connectivity between them. However, great opportunities exist to improve the quality of the matrix by designing multifunctional elements throughout the landscape. Ecosystem function and connectivity can be enhanced as the matrix is improved by multifunctionality. Although our 
knowledge of the ecological functioning of anthropogenic landscapes is growing rapidly, more research is needed to develop a better understanding of the performance of the landscape as influenced by the sum of the individual landscape elements. We argue that there are not significant technical or ecological barriers to ecological design that limit the applicability of these approaches in most landscapes. However, we do recognize that many other limitations exist, including cultural resistance, economic feasibility or efficiency, and regulatory structures, for example.

Although the current (2009) global economic condition is precarious (with many people more focused more on job security than on environmental issues), this could be an excellent time to consider design alternatives that offer long-term benefits and cost savings. Greater public funding for infrastructure projects is currently anticipated in the United States, and these projects offer a perfect opportunity to incorporate multifunctional landscape features that would improve the health of the local environment and the community. Multifunctional landscapes designed for performance would provide direct financial benefits over the long run in terms of the costs associated with waste treatment and a safe supply of water. There would be additional energy savings from the regulation of microclimates. However, the largest long-term cost reduction might be in terms of public health, where multifunctional landscapes offer access to recreational resources and healthy food crops. Such functions could contribute to reducing obesity, diabetes, and other chronic health problems. All of these benefits could result in a more stable environmental and economic climate.

Responses to this article can be read online at:

http://www.ecologyandsociety.org/voll4/iss 1/art44/ responses/

\section{LITERATURE CITED}

Ahern, J., E. Leduc, and M. L. York. 2006. Biodiversity planning and design. Island Press, Washington, D.C., USA.

Alberti, M. 2005. The effects of urban patterns on ecosystem function. International Regional Science Review 28:168-192.
Andersson, E. 2006. Urban landscapes and sustainable cities. Ecology and Society 11(1): 34. [online] URL: http://www.ecologyandsociety.org/voll1/ iss1/art34/.

Angileri, V., and A. Toccolini. 1993. The assessment of visual quality as a tool for the conservation of rural landscape diversity. Landscape and Urban Planning 24:105-112.

Arriaza, M., J. F. Canas-Ortega, J. A. CanasMadueno, and P. Ruiz-Aviles. 2004. Assessing the visual quality of rural landscapes. Landscape and Urban Planning 69:115-125.

Aschenwald, J., K. Leichter, E. Tasser, and U. Tappeiner. 2001. Spatio-temporal landscape analysis in mountainous terrain by means of small format photography: a methodological approach. IEEE Transactions on Geoscience and Remote Sensing 39:885-893.

Bailey, S. 2007. Increasing connectivity in fragmented landscapes: an investigation of evidence for biodiversity gain in woodlands. Forest Ecology and Management 238:7-23.

Baudry, J., F. Burel, S. Aviron, M. Martin, A. Ouin, G. Pain, and C. Thenail. 2003. Temporal variability of connectivity in agricultural landscapes: do farming activities help? Landscape Ecology 18:303-314.

Benton, T. G., J. A. Vickery, and J. D. Wilson. 2003. Farmland biodiversity: is habitat heterogeneity the key? Trends in Ecology and Evolution 18:182188.

Blaschke, T. 2006. The role of the spatial dimension within the framework of sustainable landscapes and natural capital. Landscape and Urban Planning 75: 198-226.

Bolund, P., and S. Hunhammar. 1999. Ecosystem services in urban areas. Ecological Economics 29:293-301.

Boutin, C., B. Jobin, and L. Belanger. 2003. Importance of riparian habitats to flora conservation in farming landscapes of southern Quebec, Canada. Agriculture, Ecosystems and Environment 94:7387.

Boutin, C., B. Jobin, L. Belanger, and L. Choiniere. 2002. Plant diversity in three types of 
hedgerows adjacent to cropfields. Biodiversity and Conservation 11:1-25.

Boyer, T., and S. Polasky. 2004. Valuing urban wetlands: a review of non-market valuation studies. Wetlands 24:744-755.

Brandt, J., and H. Vejre. 2004. Multifunctional landscapes - motives, concepts and perspectives. Pages 3-31 in J. Brandt and H. Vejre, editors. Multifunctional Landscapes Volume I: Theory, Value, and History. WIT, Boston, Massachusetts, USA.

Burger, J. 2005. Assessing environmental attitudes and concerns about a contaminated site in a densely populated suburban environment. Environmental Monitoring and Assessment 101:147-165.

Cadenasso, M. L., S. T. A. Pickett, and K. Schwarz. 2007. Spatial heterogeneity in urban ecosystems: reconceptualizing land-cover and a framework for classification. Frontiers in Ecology and the Environment 5:80-88.

Carpenter, S. R., and C. Folke. 2006. Ecology for transformation. Trends in Ecology and Evolution 21:309-315.

Chiesura, A. 2004. The role of urban parks for the sustainable city. Landscape and Urban Planning 68:129-138.

City of Portland. 2004. Stormwater management manual, revision 3. Environmental Services, Clean River Works. City of Portland, Portland, Oregon, USA.

Colding, J. 2007. 'Ecological land-use complementation' for building resilience in urban ecosystems. Landscape and Urban Planning. 81:46-55

Cook, W. J., D. G. Casagrande, D. Hope, P. M. Groffman, and S. L. Collins. 2004. Learning to roll with the punches: adaptive experimentation in human-dominated systems. Frontiers in Ecology and the Environment 2:467-474.

Costanza, R., R. d'Arge, R. de Groot, S. Farber, M. Grasso, B. Hannon, K. Limburg, S. Naeem, R. V. O'Neill, J. Paruelo, R. G. Raskin, R. Sutton, and M. van den Belt. 1997. The value of the world's ecosystem services and natural capital. Nature 387:253-260.
Daniel, T. C., and M. M. Meitner. 2001. Representational validity of landscape visualizations: the effect of graphical realism on perceived scenic beauty of forest vistas. Journal of Environmental Psychology 21(1):61-72.

de Blust, G., and M. van Olmen. 2003. Monitoring multifunctional landscapes: heading towards integrated monitoring? Pages 19-39 in J. Brandt and H. Vejre, editors. Multifunctional landscapes volume II: monitoring, diversity and management. WIT, Boston, Massachusetts, USA.

de Groot, R. 2006. Function-analysis and valuation as a tool to assess land-use conflicts in planning for sustainable, multifunctional landscapes. Landscape and Urban Planning 75:175-186.

De Sousa, C. A. 2003. Turning brownfields into green space in the City of Toronto. Landscape and Urban Planning 62:181-198.

Diekelmann, J., and R. Schuster. 2002. Natural landscaping: designing with native plant communities. The University of Wisconsin Press, Madison, Wisconsin, USA.

Doing, H. 1997. The landscape as an ecosystem. Agriculture, Ecosystems, and Environment 63:221225.

Doron, G. 2005. Urban agriculture: small, medium, large. Architectural Design 75:52-59.

Dramstad, W. E., J. D. Olson, and R. T. T. Forman. 1996. Landscape ecology principles in landscape architecture and land-use planning. Island Press, Washington, D.C., USA.

Dramstad, W. E., M. S. Tveit, W. J. Fjellstad, and G. L. A. Fry. 2006. Relationships between visual landscape preferences and map-based indicators of landscape structure. Landscape and Urban Planning 78:465-474.

Dunnett, N., and A. Clayden. 2007. Rain gardens: managing water sustainably in the garden and designed landscape. Timber Press, Portland, Oregon, USA.

Earth Pledge. 2005. Green roofs: ecologicaldesign and construction. Schiffer, Atglen, Pennsylvania, USA. 
Erickson, D. L. 2004. The relationship of historic city form and contemporary greenway implementation: a comparison of Milwaukee, Wisconsin (USA) and Ottawa, Ontario (Canada). Landscape and Urban Planning 68:199-221.

Farber, S., R. Costanza, D. L. Childers, J. Erickson, K. Gross, M. Grove, C. S. Hopkinson, J. Kahn, S. Pincelt, A. Troy, P. Warren, and M. Wilson. 2006. Linking ecology and economics for ecosystem management. BioScience 56:121-133.

Felson, A. J., and S. T. A. Pickett. 2005. Designed experiments: new approaches to studying urban ecosystems. Frontiers in Ecology and Environment 3:549-556.

Fischer, J., D. B. Lindenmayer, and A. D. Manning. 2006. Biodiversity, ecosystem function, and resilience: ten guiding principles for commodity production landscapes. Frontiers in Ecology and the Environment 4:80-86.

Fleischer, A., and A. Tchetchik. 2005. Does rural tourism benefit from agriculture? Tourism Management 26:493-501.

Forman, R. T. T., and L. E. Alexander. 1998. Roads and their major ecological effects. Annual Review of Ecological Systems 29:207-231.

Forman, R. T. T., and M. Godron. 1986. Landscape ecology. Wiley, New York, New York, USA.

Franco, M., A. V. D. Roux, T. A. Glass, B. Caballero, and F. L. Brancati. 2008. Neighborhood characteristics and availability of healthy foods in Baltimore. American Journal of Preventive Medicine 35:561-567.

Frank, L. D., M. A. Anderson, and T. L. Schmid. 2004. Obesity relationships with community design, physical activity, and time spent in cars. American Journal of Preventive Medicine 27:8796.

Freemark, K. E., C. Boutin, and C. J. Keddy. 2002. Importance of farmland habitats for conservation of plant species. Conservation Biology 16:399-412.

Gaston, K. J., P. H. Warren, K. Thompson, and R. M. Smith. 2005. Urban domestic gardens (IV): the extent of the resource and its associated features. Biodiversity and Conservation 14:3327-3349.

Gorenflo, L. J., and K. Brandon. 2005. Agricultural capacity and conservation in high biodiversity forest ecosystems. Ambio 34:199-204.

Greenberg, M., and M. J. Lewis. 2000. Brownfields redevelopment, preferences and public involvement: a case study of an ethnically mixed neighborhood. Urban Studies 37:2501-2514.

Groenfeldt, D. 2006. Multifunctionality of agricultural water: looking beyond food production and ecosystem services. Irrigation and Drainage 55:73-83.

Hellmund, P. C., and D.S. Smith. 2006. Designing greenways - sustainable landscapes for nature and people. Island Press, Washington, D.C., USA.

Hough, M. 1983. The urban landscape: the hidden frontier. Bulletin of the Association for Preservation Technology 15:9-14.

Jacke, D., and E. Toensmeier. 2005. Edible forest gardens: volume one: ecological vision and theory for temperate climate permaculture. Chelsea Green, River Junction, Vermont, USA.

Jackson, L. E. 2003. The relationship of urban design to human health and condition. Landscape and Urban Planning 64:191-200.

Jim, C. Y., and W. Y. Chen. 2006a. Perception and attitude of residents toward urban green spaces in Guangzhou (China). Environmental Management 38:339_ 349.

Jim, C. Y., and W. Y. Chen. 2006b. Recreationamenity use and contingent valuation of urban green spaces in Guangzhou, China. Landscape and Urban Planning 75:81-96.

Jo, H. K., and E. G. McPherson. 2001. Indirect carbon reduction by residential vegetation and planting strategies in Chicago, USA. Journal of Environmental Management 61:165-177.

Jobin, B., L. Belanger, C. Boutin, and C. Maisonneuve. 2004. Conservation value of agricultural riparian strips in the Boyer River watershed, Quebec (Canada). Agriculture, Ecosystems and Environment 103:413-423. 
Kaplan, R. 2001. The nature of the view from home - psychological benefits. Environment and Behavior 33:507-542.

Kaplan, R., and S. Kaplan. 1989. The experience of nature: a psychological perspective. Cambridge University Press, Cambridge, UK.

Kasanko, M., J. I. Barredo, C. Lavalle, N. McCormick, L. Demicheli, V. Sagris, and A. Brezger. 2006. Are European cities becoming dispersed? A comparative analysis of 15 European urban areas. Landscape and Urban Planning 77:111130.

Kremen, C., and R. S. Ostfeld. 2005. A call to ecologists: measuring, analyzing, and managing ecosystem services. Frontiers in Ecology and Environment 3:540-548.

Laacke, R. J. 1995. Building a decision-support system for ecosystem management-Klems experience. AI Applications 9:115-127.

Lee, K. H., T. M. Isenhart, and R. C. Schultz. 2003. Sediment and nutrient removal in an established multi-species riparian buffer. Journal of Soil and Water Conservation 58.

León, M. C., and C. A. Harvey. 2006. Live fences and landscape connectivity in a neotropical agricultural landscape. Agroforestry Systems 68: $15-26$.

Leopold, A. 1933. Game management. University of Wisconsin Press, Madison, Wisconsin, USA.

Levi, D., and S. Kocher. 2006. The use of coastal brownfields as nature preserves. Environment and Behavior 38:802-819.

Liu, J., T. Dietz, S. R. Carpenter, M. Alberti, C. Folke, E. Moran, A. N. Pell, P. Deadman, T. Kratz, J. Lubchenco, E. Ostrom, Z. Ouyang, W. Provencher, C. L. Redman, S. H. Schneider, and W. W. Taylor. 2007. Complexity of coupled human and natural systems. Science 317:1513-1516.

Loram, A., J. Tratalos, P. H. Warren, and K. J. Gaston. 2007. Urban domestic gardens (X): the extent and structure of the resource in five major cities. Landscape Ecology 22:601-615.
Lovell, S. T., and D. M. Johnston. 2009. Creating multifunctional landscapes-how can the field of ecology inform the design of the landscape? Frontiers in Ecology and the Environment. 7:in press. DOI: 10.1890/070178.

Lovell, S. T., and W. C. Sullivan. 2006. Environmental benefits of conservation buffers in the United States: evidence, promise, and open questions. Agriculture, Ecosystems and Environment 112:249-260.

Lowrance, R., S. Dabney, and R. Schultz. 2002. Improving water and soil quality with conservation buffers. Journal of Soil and Water Conservation 57:37A-43A.

McAleese, J. D., and L. L. Rankin. 2007. Gardenbased nutrition education affects fruit and vegetable consumption in sixth-grade adolescents. Journal of the American Dietetic Association 107:662-665.

McDonnell, M. J., S. T. A. Pickett, P. Groffman, P. Bohlen, R. V. Pouyat, W. C. Zipperer, R. W. Parmelee, M. M. Carreiro, and K. Medley. 1997. Ecosystem processes along an urban-to-rural gradient. Urban Ecosystems 1:21-36.

McKinney, M. L. 2002. Urbanization, biodiversity, and conservation. BioScience 52:883-890.

McNeely, J. A., and S. J. Scherr. 2003. Ecoagriculture-strategies to feed the world and save wild biodiversity. Island Press, Washington, D. C., USA.

Miller, J. R., and R. J. Hobbs. 2002. Conservation where people live and work. Conservation Biology 16:330-337.

Mitsch, W. J., J. W. Day, J. W. Gilliam, P. M. Groffman, D. L. Hey, G. W. Randall, and N. M. Wang. 2001. Reducing nitrogen loading to the Gulf of Mexico from the Mississippi River Basin: strategies to counter a persistent ecological problem. BioScience 51(5):373-388.

Mitsch, W. J., and J. G. Gosselink. 2000. Wetlands. Third edition. Wiley, New York, New York, USA.

Mungasavalli, D. P., and T. Viraraghavan. 2006. Constructed wetlands for stormwater management: 
a review. Fresenius Environmental Bulletin 15:13631372.

Naiman, R. J.,H.Decamps, and M.Pollock. 1993. The role of riparian corridors in maintaining regional biodiversity. Ecological Applications 3:209-212.

Nassauer, J. I., and R. C. Corry. 2004. Using normative scenarios in landscape ecology. Landscape Ecology 19:343-356.

Nordlind, E., and L. Ostlund. 2003. Retrospective comparative analysis as a tool for ecological restoration: a case study in a Swedish boreal forest. Forestry 76:243-251.

Oberndorfer, E. J., Lundholm, B. Bass, R. R. Coffman, H. Doshi, N. Dunnett, S. Gaffin, M. Kohler, K. K. Y. Liu, and B. Rowe. 2007. Green roofs as urban ecosystems: ecological structures, functions, and services. BioScience 57(10):823833.

Otte, A., D. Simmering, and V. Wolters. 2007. Biodiversity at the landscape level: recent concepts and perspectives for multifunctional land-use. Landscape Ecology 22:639-642.

Ozdemir, A., and O. Yilmaz. 2008. Assessment of outdoor school environments and physical activity in Ankara's primary schools. Journal of Environmental Psychology 28:287-300.

Paine, L. K., and C. A. Ribic. 2002. Comparison of riparian plant communities under four land management systems in southwestern Wisconsin. Agriculture, Ecosystems and Environment 92:93105.

Perfecto, I., and J. Vandermeer. 2002. Quality of agroecological matrix in a tropical landscape: ants in coffee plantations in Southern Mexico. Conservation Biology 16(1): 174-182.

Peterson, G. D., T. D. Beard, B. E. Beisner, E. M. Bennet, S. R. Carpenter, G. S. Cumming, C. L. Dent, and T. D. Havlicek. 2003. Assessing future ecosystem services: a case study of the Northern Highlands Lake District, Wisconsin. Conservation Ecology 7(3):1.

Pickett, S. T. A., W. R. Burch, S. E. Dalton, T. W. Foresman, J. M. Grove, and R. Rowntree. 1997.
A conceptual framework for the study of human ecosystems in urban areas. Urban Ecosystems 1:185199.

Poor, P. J. 1999. The value of additional central flyway wetlands: the case of Nebraska's Rainwater Basin wetlands. Journal of Agricultural and Resource Economics 24:253-265.

Pullar, D. V., Tidey, M. E. 2001. Coupling 3D visualization to qualitative assessment of built environment designs. Landscape and Urban Planning 55(1):29-40.

Roe, J. H., and A. Georges. 2007. Heterogeneous wetland complexes, buffer zones, and travel corridors: landscape management for freshwater reptiles. Biological Conservation 135:67-76.

Saiz, S., D. Kennedy, B. Bass, and K. Pressnail. 2006. Comparative life cycle assessment of standard and green roofs. Environmental Science and Technology 40:4312-4316.

Santelmann, M., K. Freemark, J. Sifneos, and D. White. 2006. Assessing effects of alternative agricultural practices on wildlife habitat in Iowa, USA. Agriculture, Ecosystems and Environment 113(1-4):243-253.

Schoeneberger, M. M., G. Bentrup, and C. A. Francis. 2001. Ecobelts: reconnecting agriculture and communities. Pages 238-260 in C. Flora, editor. Interaction between agroecosystems and rural communities. CRC Press, Boca Raton, Florida, USA.

Schuller, D., H. Brunken-Winkler, P. Busch, M. Forster, P. Janiesch, R. von Lemm, R. Niedringhaus, and H. Strasse. 2000. Sustainable land-use in an agriculturally misused landscape in northwest Germany through ecotechnical restoration by a 'Patch-Network-Concept'. Ecological Engineering 16:99-117.

Schultz, R. C., A. Kuehl, J. P. Colletti, P. Wray, T. Isenhart, and L. Miller. 1997. Riparian buffer systems. Publication Pm-1626a. Iowa State University, Ames, Iowa, USA.

Seto, K. C., and M. Fragkias. 2005. Quantifying spatiotemporal patterns of urban land-use change in four cities of China with time series landscape metrics. Landscape Ecology 20:871-888. 
Shafer, C. S., B. K. Lee, and S. Turner. 2000. A tale of three greenway trails: user perceptions related to quality of life. Landscape and Urban Planning 49:163-178.

Shashua-Bar, L., M. E. Hoffman, and Y. Tzamir. 2006. Integrated thermal effects of generic built forms and vegetation on the UCL microclimate. Building and Environment 41:343-354.

Smith, R. M., K. J. Gaston, P. H. Warren, and K. Thompson. 2005. Urban domestic gardens (V): relationships between landcover composition, housing and landscape. Landscape Ecology 20:235-253.

Smith, K. L., R. J. Baldwin, R. C. Glatts, T. K. Chereskin, H. Ruhl, and V. Lagun. 2003. Weather, ice, and snow conditions at Deception Island, Antarctica: long time-series photographic monitoring. Deep-Sea Research Part II - Tropical Studies in Oceanography 50:1649-1664.

Swift, M. J., A. M. N. Izac, and M. van Noordwijk. 2004. Biodiversity and ecosystem services in agricultural landscapes-are we asking the right questions? Agriculture, Ecosystems and

Environment 104:113-134.

Tajima, K. 2003. New estimates of the demand for urban green space: implications for valuing the environmental benefits of Boston's Big Dig project. Journal of Urban Affairs 25:641-655.

Thompson, W., and K. Sorvig. 2000. Sustainable landscape construction: a guide to green building outdoors. Island Press, Washington, D.C., USA.

Todd, J., E. J. H. Brown, and E. Wells. 2003. Ecological design applied. Ecological Engineering 20:421-440.

Tress, B., and G. Tress. 2003. Scenario visualization for participatory landscape planning - a study from Denmark. Landscape and Urban Planning 64(3):161-178.

Troll, C. 1950. The geographic landscape and its investigation. Pages 71-101 in J. A. Weins, M. R. Moss, M. G. Turner, D. J. Mladenoff, editors.
Foundation papers in landscape ecology. 2006. Columbia University Press, New York, New York, USA.

Tscharntke, R., A. M. Klein, A. Kruess, I. SteffanDewenter, and C. Thies. 2005. Landscape perspectives on agricultural intensification and biodiversity-ecosystem service management. Ecology Letters 8:857-874.

Tyndall, J.C., and J.P. Colletti. 2001. Shelterbelts, livestock odor mitigation, and sustainable agriculture: a research framework. Pages 206-219 in W. Schroeder and J. Kort, editors. Temperate agroforestry: adaptive and mitigative roles in a changing physical and socio-economic climate. Proceedings of the $7^{\text {th }}$ biennial conference on agroforestry in North America and $6^{\text {th }}$ annual conference of the Plains and Prairie Forestry Association, 12-15 August 2001. Regina, Saskatchewan, Canada.

US Census Bureau. 2008. International Data Base. Accessed 8 April, 2009.

U.S. Department of Agriculture. 2000. Conservation buffers to reduce pesticide losses. Natural Resources Conservation Service, Washington, D. C., USA.

Vandermeer, J. and B. B. Lin. 2008. The importance of matrix quality in fragmented landscapes: understanding ecosystem collapse through a combination of deterministic and stochastic forces. Ecological Complexity 5(3):222 227.

Vandermeer, J., M. van Norrdwijk, J. Anderson, C. Ong, and I. Perfecto. 1998. Global change and multi-species agroecosystems: concepts and issues. Agriculture, Ecosystems and Environment 67:1-22.

Viljoen, A., editor. 2005. Continuous productive urban landscapes: designing urban agriculture for sustainable cities. Architectural Press, London, UK.

Wania, A., I. Kuhn, and S. Klotz. 2006. Plant richness patterns in agricultural and urban landscapes in Central Germany-spatial gradients of species richness. Landscape and Urban Planning 75:97-110. 
Wiggering, H., K. Muller, A. Werner, and A. Helming. 2003. The concept of multifunctionality in sustainable land development. Pages 3-18 in K. Helming and H. Wiggering, editors. Sustainable Development of Multifunctional Landscapes. Springer-Verlag, Berlin, Germany.

Wilson, K. A., E. C. Underwood, S. A. Morrison, K. R. Klausmeyer, W. W. Murdoch, B. Reyers, G. Wardell-Johnson, P. A. Marquet, P. W. Rundel, M. F. McBride, R. L. Pressey, M. Bode, J. M. Hoekstra, S. Andelman, M. Looker, C. Rondinini, P. Kareiva, M. R. Shaw, and H. P. Possingham. 2007. Conserving biodiversity efficiently: what to do, where, and when. Plos Biology 5(9):1850-1861.

Wollenburg, E., D. Edmunds, and L. Buck. 2000. Using scenarios to make decisions about the future: anticipatory learning for the adaptive comanagement of community forests. Landscape and Urban Planning 47(1-2):65-77.

World Health Organization. 2003. Joint WHO/ FAO expert consultation on diet, nutrition, and the prevention of chronic diseases. WHO technical report series 916. Geneva, Switzerland. 